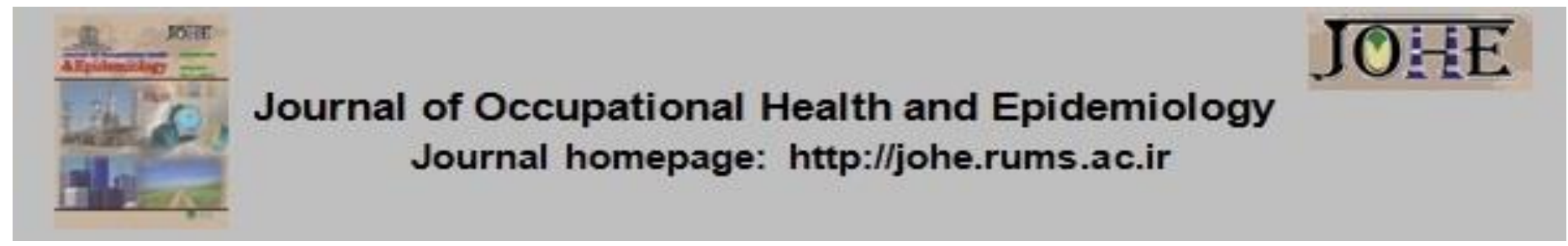

\title{
Prevalence of Metabolic Syndrome and Associated Factors among Workers: The Case of Two Port Companies in Cotonou, Benin (2019)
}

\author{
Hinson Antoine Vikkey ${ }^{1^{*}}$, Adjobimey Menonli², Aguemon Badirou ${ }^{3}$, Dossou-Togbe Marie-Axelle I², \\ Mikponhoue Rose ${ }^{2}$, Mama Cisse Ibrahim ${ }^{4}$, Gounongbe Fabien ${ }^{5}$, Ayelo Paul ${ }^{6}$ \\ 1. Associate Prof., Dept of Public Health, Unit of Teaching and Research in Occupational and Environmental Health, Faculty of Health \\ Sciences, University of Abomey-Calavi, 01 PO188 Cotonou, Benin. \\ 2. Assistant Prof, Dept of Public Health, Unit of Teaching and Research in Occupational and Environmental Health, Faculty of Health \\ Sciences, University of Abomey-Calavi, 01 PO188 Cotonou, Benin. \\ 3. Associate Prof., Dept of Public Health, Unity of Teaching and Research in Public Health Faculty of Health Sciences, University of \\ Abomey-Calavi, 01 PO188 Cotonou, Benin. \\ 4. Assistant Prof, Faculty of Medicine, University of Parakou, Benin. \\ 5. Associate Prof., Faculty of Medicine, University of Parakou, Benin. \\ 6. Professor, Dept of Public Health, Unit of Teaching and Research in Occupational and Environmental Health, Faculty of Health \\ Sciences, University of Abomey-Calavi, 01 PO188 Cotonou, Benin.
}

$$
\begin{aligned}
& \text { Citation: Vikkey HA, Menonli A, Badirou A, Marie-Axelle I DT, Rose M, Ibrahim MC, Fabien } \\
& \text { G, Paul A. Prevalence of Metabolic Syndrome and Associated Factors among Workers: The } \\
& \text { Case of Two Port Companies in Cotonou, Benin (2019). J Occu Health Epidemiol 2021; } \\
& \text { 10(3):140-9. }
\end{aligned}
$$

\section{Article Info}

\section{* Corresponding author: \\ Hinson Antoine Vikkey, E-mail: \\ hinsvikkey@yahoo.fr}

\section{Article history \\ Received: Aug 2021 \\ Accepted: Nov 2021}

10.52547/johe.10.3.140

Print ISSN: 2251-8096 Online ISSN: 2252-0902

Peer review under
responsibility of Journal of
Occupational Health and
Epidemiology

\section{Abstract}

Background: Metabolic Syndrome (MetS) is developed by a combination of several risk factors, which can increase the likelihood of cardiovascular diseases and diabetes. The present study aimed to evaluate the prevalence of MetS and its associated factors among Cotonou Port workers.

Materials and Methods: This cross-sectional study was conducted for descriptive and analytical purposes. The administration of the questionnaire was inspired by WHO STEPS, with biological examinations performed. MetS was selected according to the criteria of the International Diabetes Federation (IDF). The data were analyzed using $R$ 3.6.1 software. Besides, a univariate analysis and a multivariate logistic regression analysis were performed to determine MetS-associated factors.

Results: Our study population consisted of a total of 349 workers aged 23 to 64 years. Besides, the prevalence of MetS was $18.1 \%$. The most common features of the workers were blood pressure $\geq 130 / 85 \mathrm{mmHg}(92.1 \%)$ followed by abdominal obesity $(76.3 \%)$ and glycemia $\geq 1 \mathrm{~g} / \mathrm{l}(65.1 \%)$. After multivariate analysis, factors associated with MetS included age $>50$ years $(\mathrm{ORa}=3.97 \mathrm{Cl} 95 \%[1.71-9.36], \mathrm{p}=0.006)$, alcoholism $(\mathrm{ORa}=$ 2.05; Cl95\% [1.07 - 4.15], $\mathrm{p}=0.031$ ), family history of hypertension (ORa $=2.08 ; \mathrm{Cl} 95 \%$ [1.11 - 4.01], $p=0.022)$, overweight $(\mathrm{ORa}=4.87 \mathrm{Cl}$ (95\% [2.10 -12.75$], p=0.001)$ and obesity (ORa $=5.80 \mathrm{Cl}$ (95\% [2.42 - 15.59], $p=0.001)$.

Conclusion: The MetS frequency is high among Cotonou Port workers. Accordingly, it is necessary to identify the related risks to take adequate preventive measures and to promote the workers' health.

Keywords: Metabolic Syndrome, Workplace, Benin.

\section{Introduction}

Metabolic syndrome (MetS) is one of the major public health problems, in which a combination of several metabolic disturbances occurs in an individual, with each predisposing the person to cardiovascular risks and/or diabetes a well as their complications [1]. Given the current trend of 
globalization and economic growth, the increased prevalence of MetS has been attributed to lifestyle changes, including new eating habits and physical inactivity [2]. In addition, modern life imposes considerable changes to the work environment, which further exposes workers to a sedentary lifestyle and inactivity [3]. In addition, the burden of morbidity and mortality caused by complications of risk factors (hypertension, diabetes, obesity, etc.) leads to socioeconomic repercussions in terms of health expenditures, work absenteeism, and reduced national productivity [4].

Various definitions have been proposed by different organizations for MetS over time with no broad consensus. The International Diabetes Federation (IDF) and the American Heart Association/National Heart, Lung and Blood Institute (AHA/NHLBI) recently showed their desire to provide a single definition to be used worldwide. The prevalence of MetS varies among populations [5-7]. For example, in the United States, the prevalence of MetS increased from 32.9\% in 2004 to $34.7 \%$ in 2015 according to the NCEP-ATP III criteria [6]. Globally, the prevalence of MetS ranges from 10 to $40 \%$ [7]. It increases the risk of type 2 diabetes fivefold and the risk of developing CVD twofold [8]. In addition, patients with MetS have 2 to 4 times higher the risk of dying from a cardiovascular event than those without MetS [5]. In Africa, the MetS prevalence rate among shift workers and non-shift workers at a power plant in Tunisia was 51.2 and $27.2 \%$, respectively [9]. Besides, the rate was $21.7 \%$ among healthcare workers in Morocco [10]. The prevalence of MetS in Burkina Faso and Togo was 15.1 and 18.3\%, respectively, among employees and workers in a telecommunications company [11, 12]

In Benin, like most developing countries, several studies have been conducted on the prevalence of MetS in the general population, yet few of them have investigated its impact in the workplace. Workers in port companies are exposed to heavy workloads due to the speed at which they have to process files as well as to prolonged periods of sitting, all of which exposing them to the risk of MetS. Moreover, during medical surveillance of the workers of these companies, several cases of cardiovascular events were recorded annually. To better perform the prevention of cardiovascular events, the present study was conducted on the workers of two port companies in Cotonou. Against this backdrop, the present study aims to determine the prevalence of MetS and its associated factors in this socio-professional group in the field of activity forming the hub of the Beninese economy.

\section{Materials and Methods}

This descriptive study was conducted in Cotonou, from June to November, 2019. Using nonprobability sampling, we recruited all workers of two companies (one from the public sector and the other from the private sector) who met our inclusion criteria. The inclusion criteria were having an indefinite contract, having at least one year of seniority, and having participated in the clinical examination and blood sampling stages. Workers not included in the study were pregnant women as well as individuals with a pathologic history of endocrinopathy, diabetes, hypertension, and dyslipidemia before employment. Besides, individuals unable to complete the clinical examination and/or biological workup were excluded from the study.

The sample size was 328 that was calculated using the Schwartz formula $n=(Z \alpha)^{2} p q / i^{2} ; \alpha=5 \%$ and $Z \alpha=1.96 ; p=26.5 \%$ prevalence of MetS in the workplace in Togo [12], $q=1-p=73.5 \% ; i=$ $5 \%$ [desired precision] with a $10 \%$ add-on.

Data collection was performed using the WHO STEPwise questionnaire for the screening and surveillance of Non-Communicable Diseases [NCD]. Besides, data were collected in three stages. The questionnaire was distributed to explore socio-professional data, lifestyle habits, family and personal pathological history of diabetes, hypertension, stroke, and dyslipidemia.

Physical examination of the patients was fully performed by a team of occupational physicians, and anthropometric data were collected by two trained nurses.

Physical measuring instruments, including mechanical scales for adults [model 761, SECA], height measurement tools, and graduated flexible metric tapes were used as the basis for the collection of data necessary for our study (weight, height, and waist circumference). Besides, blood pressure was measured using an electronic blood pressure monitor (SPENGLER brand) equipped with an adapted cuff. In addition, blood pressure was taken in the sitting position after taking rest for at least 15 minutes.

Next, 12-hour fasting subjects underwent biochemical examinations. The blood sample was taken in a dry tube and in a tube with anticoagulant "Ethylene-Diamine-Tetra-Acetic (EDTA)" by a laboratory technician at the workplace. The blood sample was taken through venous sampling. In addition, biological analyses were performed in the laboratory of the clinic in charge of the follow-up of the personnel of the companies. All measurements were standardized according to the rules used in 
the aforesaid laboratory.

Concerning blood sugar, a colorimetric assay was performed following two coupled enzymatic reactions. The enzyme-specific reaction (glucose oxidase) oxidized the glucose present in the sample to gluconic acid, and the second reaction formed a colored product in the presence of peroxidase.

Concerning HDL cholesterol, low-density lipoproteins were precipitated by phosphotungtic acid and magnesium ions and separated by centrifugation. The high-density lipoproteins remained in suspension, having been determined by the clear superngent.

For triglycerides, a colorimetric assay was performed following enzymatic reactions. Triglycerides were hydrolyzed to glycerol and fatty acid. An enzyme-specific reaction (glycerol phosphate-oxidase) oxidized glycerol-3-phosphate, which was turned into glycerol-3-phosphate oxidase while releasing hydrogen peroxide as a result of the action of glycerol kinase on glycerol.

Reading was performed for the three blood samples with an automated spectrophotometer. When the medium changed color, the intensity of the coloring would depend on blood sampling, having been proportional to the concentration of the serum glucose, the serum in total cholesterol, or serum triglycerides.

The dependent variable was metabolic syndrome. We adopted the most recent harmonized definition proposed by FID/AHA/NHLBI in 2009, which defined metabolic syndrome as the combination of at least three of the following criteria; a) abdominal obesity with the waist size $\geq 80 \mathrm{~cm}$ in women and $\geq$ $94 \mathrm{~cm}$ in men; b) hypertriglyceridemia being equal to triglycerides, being and $\geq 1,71 \mathrm{mmol} / \mathrm{L}$ or $1.50 \mathrm{~g} / \mathrm{L} ; \mathrm{c})$, with low HDL cholesterol $\leq$ $1.03 \mathrm{mmol} / \mathrm{l}$ or $0.40 \mathrm{~g} / \mathrm{l}$ in men and $\leq 1.29 \mathrm{mmol} /$ or $0.50 \mathrm{~g} / \mathrm{l}$ in women or specific treatment of this anomaly; d) an increase in the blood pressure occurring corresponding to the systolic blood pressure $\geq 130 \mathrm{mmHg}$ or diastolic $\geq 85 \mathrm{mmHg}$, or hypertension treated; e) fasting blood sugar being $\geq$ to $5.6 \mathrm{mmol} / \mathrm{L}$ or $1.0 \mathrm{~g} / \mathrm{L}$, or it would be known as diabetic, or it would to be under antidiabetic treatment. The diagnosis of MetS was evaluated by occupational physicians.

The independent variables studied included sociodemographic variables (age, sex, marital status, and level of education), socio-professional variables (length of the service at work, type of the position, period of work, and stress with the visual evaluation scale), behavioral variables (consumption of alcohol and/or tobacco, caloric diet, diet high in salt or sugar, consumption of fruits and vegetables, and the level of physical activity), and clinical variables (family history of hypertension and diabetes and the body mass index [BMI]). The BMI was classified as normal being between 18 and $25 \mathrm{~kg} / \mathrm{m} 2$, with overweight being between 25 and $30 \mathrm{~kg} / \mathrm{m} 2$, and obese being $\geq 30 \mathrm{~kg} / \mathrm{m} 2$.

The data were entered in the Epi-Data Entry software V3.1 and analyzed with the R 3.6.1 software. Besides, qualitative variables were described as proportions, with quantitative variables expressed as averages \pm standard deviation. In the univariate analysis, the proportions were compared using the Pearson's Chi-square $(x 2)$ test, and the averages were compared using the student's t-test. Additionally, all variables with a $p$-value less than 0.25 were retained for the logistic regression analysis. Using the stepwise descending method in the multivariate analysis, a binary logistic regression was performed to find the factors associated with MetS. The association between the studied factors and MetS was determined by the raw and adjusted Odds Ratio (OR) along with their 95\% confidence intervals $(\mathrm{Cl})$. In addition, the significance level chosen for the tests was $p \leq 0.05$.

Permission was obtained from the companies' managers, and informed consent was obtained from the participants. Besides, data were collected by meeting confidentiality and human rights requirements. The study was performed in the course of the workers' annual medical visits. Permission was not obtained from the Ethics Committee, but the study was registered under number $\mathrm{N}^{\circ} 2204$ at the Faculty of Health Sciences of the University of Abomey-Calavi.

\section{Results}

Sociodemographic features: Based on the inclusion criteria, 349 workers were interviewed by the end of the study. The mean age of the study population was $38 \pm 8$ years, with the minimum and maximum age having been 23 and 64 years, respectively. The sex ratio in our study was 4.2 in favor of the males. Almost two-thirds (73.6\%) of the workers had a university education background, and $83.4 \%$ of them were couples (married or living together). Table 1 shows the distribution of the port enterprise workers in terms of sociodemographic characteristics in Cotonou, BENIN in 2019. 
Table 1. Distribution of the workers in two port companies by sociodemographic characteristics in Cotonou, Benin, 2019 $(n=349)$

\begin{tabular}{|c|c|c|c|c|c|c|c|c|}
\hline & & \multicolumn{2}{|c|}{$\begin{array}{c}\text { Male } \\
n=282\end{array}$} & \multicolumn{2}{|c|}{$\begin{array}{c}\text { Female } \\
n=67\end{array}$} & \multicolumn{2}{|c|}{$\begin{array}{c}\text { Total } \\
n=349\end{array}$} & \multirow[t]{2}{*}{ P-value } \\
\hline & & Effective & $\%$ & Effective & $\%$ & Effective & $\%$ & \\
\hline \multirow{4}{*}{$\begin{array}{c}\text { Age } \\
\text { group } \\
\text { (years) }\end{array}$} & $23-34$ & 101 & 28.94 & 41 & 11.75 & 142 & 40.69 & \multirow{3}{*}{0.0002} \\
\hline & $35-49$ & 133 & 38.11 & 23 & 6.59 & 156 & 44.70 & \\
\hline & $50-64$ & 48 & 13.75 & 3 & 0.86 & 51 & 14.61 & \\
\hline & Mean age & $39 \pm 9$ & & $34 \pm 6$ & & $38 \pm 8$ & & \\
\hline \multirow{3}{*}{$\begin{array}{l}\text { Level of } \\
\text { instruction }\end{array}$} & Primary & 15 & 1.30 & 1 & 0.29 & 16 & 4.58 & \multirow{3}{*}{0.274} \\
\hline & Secondary & 74 & 21.20 & 2 & 0.57 & 76 & 21.78 & \\
\hline & University & 193 & 55.30 & 64 & 16.33 & 257 & 73.64 & \\
\hline \multirow{3}{*}{ Marital status } & Married & 184 & 52.72 & 39 & 11.18 & 223 & 63.90 & \multirow{3}{*}{0.102} \\
\hline & Concubinage & 56 & 16.04 & 12 & 3.44 & 68 & 19.48 & \\
\hline & Single & 42 & 12.04 & 16 & 4.58 & 58 & 16.62 & \\
\hline
\end{tabular}

Professional features: Most of the workers in our study $(85.96 \%)$ were in technical positions, and more than one third of them (71.9\%) did shift work.
Besides, a total of $56.16 \%$ of the workers felt that they did not experience or feel any work-related stress. Table 2 shows the occupational features.

Table 2. Distribution of the workers in two port companies by occupational characteristics in Cotonou, Benin, in 2019 ( $n=$ 349)

\begin{tabular}{|c|c|c|c|c|c|}
\hline & & $\begin{array}{c}\text { Male } \\
\mathrm{n}=282(\%)\end{array}$ & $\begin{array}{l}\text { Female } \\
n=67(\%)\end{array}$ & $\begin{array}{c}\text { Total } \\
\mathrm{n}=349(\%)\end{array}$ & P-value \\
\hline \multirow{3}{*}{ Workstation } & Administrative & $15(4.30)$ & $10(2.86)$ & $25(7.16)$ & \multirow{3}{*}{$<0.0002$} \\
\hline & Traders & $3(0.86)$ & $21(6.02)$ & $24(6.88)$ & \\
\hline & Technical & $264(75.64)$ & $36(10.32)$ & $300(85.96)$ & \\
\hline \multirow{2}{*}{ Shift work } & Alternate & $200(57.30)$ & $51(14.62)$ & 251 (71.92) & \multirow{2}{*}{0.484} \\
\hline & Daytime work & $82(23.50)$ & $16(4.58)$ & $98(28.08)$ & \\
\hline \multirow{2}{*}{$\begin{array}{l}\text { Occupational } \\
\text { stress }\end{array}$} & Yes & $123(35.24)$ & $30(8.60)$ & $153(43.84)$ & \multirow{2}{*}{0.102} \\
\hline & No & 159 (45.56) & 37 (10.60) & $196(56.16)$ & \\
\hline
\end{tabular}

Behavioral features: About one third (36.1\%) of the subjects stated that they consumed alcohol only occasionally, with higher consumption rates reported in males than in females $(p=0.048)$. In our study, $74.5 \%$ of the subjects considered themselves average eaters, and $51.9 \%$ reported that they had high levels of activity. Accordingly, walking accounted for $35.2 \%$ of the most practiced physical activity.

Clinical and biological features: High blood pressure and diabetes were the two most common family histories in our study, and their frequencies were 51.0 and $30.6 \%$, respectively, in the 349 workers surveyed. Besides, obese and overweight workers amounted to 89 (25.5\%) and 125 (35.8\%) individuals, respectively. Accordingly, $61.3 \%$ of the subjects in the study population were overweight with the clear predominance of women $(73.2 \%$ vs $58.6 \%$ ).

The average blood sugar was $5.28 \mathrm{mmol} / \mathrm{l} \pm 2.14$ $\mathrm{mmol} / \mathrm{l}$ with the maximum and minimum values of 3.41 and $25.46 \mathrm{mmol} / \mathrm{l}$, respectively. Besides, $24.6 \%$ of the employees had a blood glucose level of $>5.5 \mathrm{mmol} / \mathrm{L}$. The proportion of the known diabetic subjects in our subjects was $22.2 \%$. Besides, the mean blood triglyceride concentration was $0.97 \pm 0.42 \mathrm{mmol} / \mathrm{l}$, with the minimum and maximum values of 0.11 and $3.37 \mathrm{mmol} / \mathrm{l}$, respectively. In total, 27 (7.7\%) workers, including $1(1.5 \%)$ female, had hypertriglyceridemia. Besides, the average HDL cholesterol value was $1.24 \pm 0.57 \mathrm{mmol} / \mathrm{l}$ with the minimum and maximum values of 0.08 and $10.02 \mathrm{mmol} / \mathrm{l}$, respectively. Workers with HDL hypercholesterolemia amounted to 124 (35.5), of whom 89 (71.8\%) were male and $35(58.2 \%)$ were female. Table 3 shows the clinical-biological distribution of the workers in two port companies in Cotonou, Benin, in 2019. 
Table 3. Clinical-biological distribution of the workers in two port companies in Cotonou, Benin, in 2019

\begin{tabular}{lcccc}
\hline & $\begin{array}{c}\text { Male } \\
\mathbf{n = 2 8 2}\end{array}$ & $\begin{array}{c}\text { Female } \\
\mathbf{n = 6 7}\end{array}$ & $\begin{array}{c}\text { Total } \\
\mathbf{n = 3 4 9}\end{array}$ & P-value \\
\hline Body Mass Index (BMI) & & & 0.0001 \\
\hline Lean & $3(0.86)$ & $0(0.0)$ & $3(0.86)$ & \\
\hline Normal & $114(32.66)$ & $18(29.9)$ & $132(37.82)$ & \\
\hline Overweight & $109(38.70)$ & $16(23.9)$ & $125(35.81)$ & 0.0001 \\
\hline Obese & $56(19.90)$ & $33(49.3)$ & $89(25.51)$ & 0.029 \\
\hline High waist circumference & $102(36.2)$ & $49(73.1)$ & $151(43.3)$ & 0.001 \\
\hline Ligh blood pressure & $128(45.4)$ & $21(31.3)$ & $149(42.7)$ & 0.033 \\
\hline High triglycerides & $89(31.4)$ & $35(52.2)$ & $124(35.5)$ & 0.638 \\
\hline High blood sugar & $26(9.2)$ & $1(1.5)$ & $27(7.7)$ & $86(24.6)$ \\
\hline
\end{tabular}

Overall prevalence of MetS and its prevalence in the companies: The overall prevalence of metabolic syndrome in our study, according to the IDF criteria, was $18.1 \% 95 \% \mathrm{Cl}=[14.2 \%-22.6 \%]$. Out of the 63 workers with MetS, 50 (79.4\%) were male and 13 (20.6\%) were female. However, the prevalence was higher in females than in males (19.4\% vs $17.7 \%$ ), with no statistically significant difference. Besides, the prevalence increased significantly with the age of the subjects being $>50$ years $(p=0.001)$. In addition, the prevalence of MetS was $25.9 \%$ in the first company (S1 [95\% Cl $=15.5 \%-38.7 \%]$ ) versus $16.6 \%$ in the second one (S2 [95\% Cl $=12.6 \%-21 \%]$ ) with $p=0.148$.

Possible combinations and the number of criteria for MetS: The most common criteria of the workers were blood pressure $\geq 130 / 85 \mathrm{mmHg}$ (92.1\%), followed by abdominal obesity $(76.3 \%)$, glycemia $\geq$ $1 \mathrm{~g} / \mathrm{l}(65.1 \%)$, low HDL cholesterol (55.7\%), and hypertriglyceridemia (28.7\%). In fact, MetS was significantly higher in its moderate form in 44 (12.6\%) people, having an association with at least three defining criteria. One patient showed the most severe form of MetS, combining 5 criteria. The most common combination of the criteria in $25.4 \%$ of our study population was the combination of abdominal obesity, hyperglycemia, and hypertension. Fig.1 shows the status of the combined criteria.

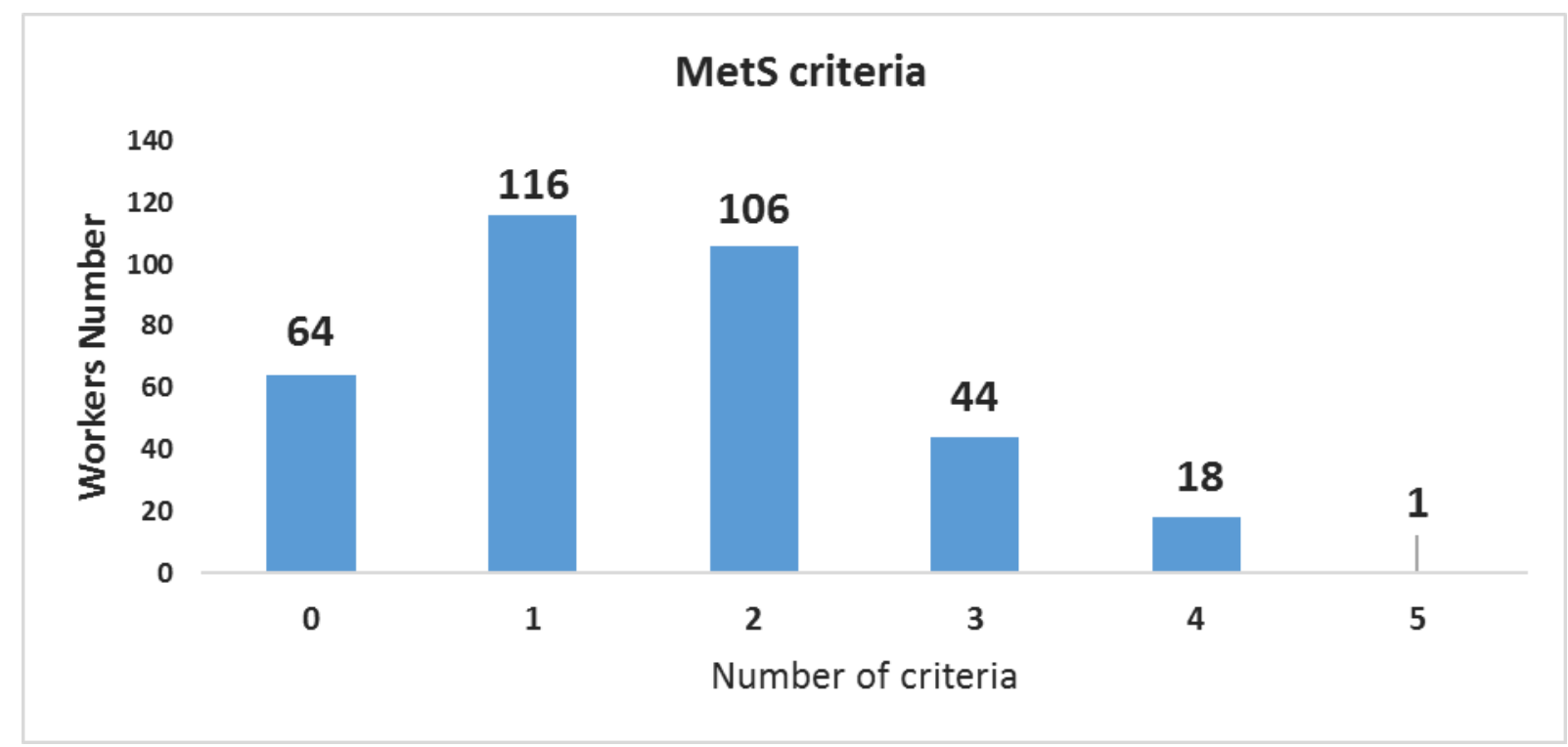

Fig. 1. Variation of MetS criteria in the workers of the two port companies $(N=349)$

Factors associated with metabolic syndrome: Multivariate analysis revealed that age $>50$ years (ORadjusted = 3.97 C195\% [1.71 - 9.36]; $p=0.006$ ), alcoholism (ORadjusted = 2.05; CI95\% [1.07 4.15]; $p=0.031$ ), family history of hypertension (ORadjusted = 2.08; Cl95\% [1.11 - 4.01]; $p=0.022$ ) , overweight (ORadjusted $=4.87 \mathrm{Cl95 \%}$ [2.10 12.75]; $p=0.001$ ), and obesity (ORadjusted $=5.80$
CI95\% [2.42 - 15.59]; $p=0.001$ ) were the major factors associated with MetS. Table 4 shows the prevalence of MetS and the associated factors according to sociodemographic, professional, behavioral, and family history features in the univariate analysis. Besides, Table 5 shows the multivariate analysis results. 
Table 4. MetS and associated factors; univariate analysis results for two port companies in Cotonou, Benin, in 2019; ( $N=$ 349)

\begin{tabular}{|c|c|c|c|c|c|c|c|}
\hline \multirow{2}{*}{\multicolumn{2}{|c|}{ Sociodemographic factors }} & \multirow{2}{*}{$\begin{array}{c}\text { Total } \\
(\mathrm{N})\end{array}$} & \multicolumn{2}{|c|}{ MetS } & \multirow{2}{*}{ OR $_{\text {crude }}$} & \multirow{2}{*}{ IC $_{95 \%}$ OR $_{\text {crude }}$} & \multirow{2}{*}{ P-value } \\
\hline & & & $\mathbf{n}$ & $\%$ & & & \\
\hline \multirow{3}{*}{ Age groups (years ) } & $23-34$ & 142 & 17 & 12.0 & 1 & - & \multirow{3}{*}{0.002} \\
\hline & $35-49$ & 156 & 29 & 18.6 & 1.68 & {$[0.88-3.21]$} & \\
\hline & $50-64$ & 51 & 17 & 33.3 & 3.68 & {$[1.70-7.95]$} & \\
\hline \multirow{3}{*}{ Level of instruction } & Primary & 282 & 50 & 17.7 & 1 & - & \multirow{3}{*}{0.274} \\
\hline & Secondary & 76 & 16 & 21.1 & 0,59 & [0.18-1.93] & \\
\hline & University & 257 & 42 & 16.3 & 0.43 & [0.14-1.30] & \\
\hline \multirow{2}{*}{ Gender } & Male & 282 & 50 & 17.7 & 1 & - & \multirow{2}{*}{0.886} \\
\hline & Female & 67 & 13 & 19.4 & 1.12 & {$[0.57-2.20]$} & \\
\hline \multirow{3}{*}{ Marital status } & Single & 58 & 6 & 10.3 & & & \multirow{3}{*}{0.102} \\
\hline & Married & 223 & 40 & 17.9 & 1.89 & {$[0.76-4.71]$} & \\
\hline & Concubinage & 68 & 17 & 25.0 & 2.89 & {$[1.05-7.91]$} & \\
\hline \multicolumn{8}{|l|}{ Occupational factors } \\
\hline \multicolumn{2}{|c|}{ Seniority $\geq 10$ years } & 51 & 14 & 27.5 & 1.92 & {$[0.97-3.82]$} & 0.090 \\
\hline \multicolumn{2}{|c|}{ Alternate shift work } & 251 & 41 & 16.33 & 0.67 & $0.34-1.20$ & 0.182 \\
\hline \multicolumn{2}{|c|}{ Administrative station work } & 25 & 5 & 20.0 & 1.14 & {$[0.41-3.18]$} & 0.792 \\
\hline \multicolumn{2}{|c|}{ Occupational perceived stress } & 153 & 29 & 19.0 & 1.11 & {$[0.64-1.93]$} & 0.698 \\
\hline \multicolumn{8}{|l|}{ Behavioural factors } \\
\hline \multicolumn{2}{|c|}{ Alcohol consumption } & 218 & 49 & 22,5 & 2,42 & {$[1.28-4.59]$} & 0.008 \\
\hline \multicolumn{2}{|c|}{ Tobacco consumption } & 10 & 2 & 20.0 & 1.14 & {$[0.24-5.50]$} & $0.871^{*}$ \\
\hline \multicolumn{2}{|c|}{ High sugar food } & 94 & 19 & 20.2 & 1.21 & {$[0.67-2.21]$} & 0.523 \\
\hline \multicolumn{2}{|c|}{ High salt food } & 64 & 14 & 21.9 & 1.35 & {$[0,69-2,63]$} & 0.378 \\
\hline \multicolumn{2}{|c|}{ High fat diet } & 70 & 16 & 22.9 & 1.46 & {$[0.77-2.77]$} & 0.242 \\
\hline \multicolumn{2}{|c|}{ Absence of physical activities } & 57 & 9 & 15.79 & 0.82 & [0.38-1.78] & 0.627 \\
\hline \multicolumn{2}{|c|}{ Absence of fruit and vegetable consumption } & 31 & 4 & 12.9 & 0.65 & [0.21-1.92] & 0.434 \\
\hline \multicolumn{8}{|l|}{ Anthropometric factors } \\
\hline \multirow{3}{*}{ BMI } & Normal/Low weight & 125 & 7 & 5.2 & 1 & - & \\
\hline & Overweight & 125 & 31 & 24.8 & 6.03 & [2.55 -14.28] & $<0.001$ \\
\hline & Obesity & 89 & 25 & 28.1 & 7.14 & {$[2.93-17.4]$} & \\
\hline & Hypertension & 178 & 43 & 24.2 & 2.40 & {$[1.36-4.37]$} & 0.002 \\
\hline Family history & Diabetes & 107 & 26 & 24.3 & 1.78 & [1.01-3.12] & 0.048 \\
\hline
\end{tabular}

${ }^{*}$ Fisher

Table 5. MetS and associated factors; multivariate analysis in two port companies in Cotonou, Benin, in 2019; ( $N=349)$

\begin{tabular}{|c|c|c|c|c|}
\hline & iable & OR adjusted & IC $_{95 \%}$ OR $_{\text {adjusted }}$ & P-value \\
\hline \multirow{3}{*}{$\begin{array}{l}\text { Age groups } \\
\text { (years) }\end{array}$} & $23-34$ & - & - & \multirow{3}{*}{0.006} \\
\hline & $35-49$ & 1.46 & [0.74-2.96] & \\
\hline & $50-64$ & 3.97 & {$[1.71-9.36]$} & \\
\hline \multirow{3}{*}{ BMI } & Normal/Low weight & - & - & \multirow{3}{*}{$<0.001$} \\
\hline & Overweight & 4.87 & [2.10-12.75] & \\
\hline & Obesity & 5.80 & [2.42-15.59] & \\
\hline \multicolumn{2}{|c|}{ Alcohol consumption } & 2.05 & [1.07-4.15] & 0.031 \\
\hline \multicolumn{2}{|c|}{ Hypertension } & 2.08 & {$[1.11-4.01]$} & 0.022 \\
\hline
\end{tabular}

\section{Discussion}

The present study focused on the population of employees of two port companies in Cotonou, with indeterminate contracts. Besides, our study focused on the population of employees in two companies in the Port of Cotonou with permanent contracts. The sample size of this study was medium, which allowed us to have a representation of different professional strata during annual visits to the two companies. However, the diversity of different positions did not allow us to extend to a specific group. Most studies in the literature have been conducted mainly on the general population $[13,14]$ or on target groups, i.e. diabetics $[2,15]$, hypertensives, and the obese $[16,17]$.

In the literature reviewed in Africa, a few studies were carried out in various socio-professional 
groups, i.e. in the market [18], in a professional environment [19], among healthcare professionals in Morocco [10], and in employees of a telecommunications company in Togo [12]. The present study on the prevalence of MetS and its associated factors among workers in two port companies in Cotonou was the first one in Benin in 2019, in this field.

According to the 2009 IDF definition, the overall prevalence of MetS in this study was $18.1 \% 95 \%$ $\mathrm{Cl}=[14.2 \%-22.6 \%]$. This prevalence of MetS was close to the results achieved by Ouedraogo et al (2016) (18.3\%) in the workplace [19]. Laraqui et al (2017) [10] and Hinson et al (2017) [12] reported a higher prevalence of MetS than ours (21.7 vs $26.5 \%$ ) in their studies among healthcare professionals in Morocco and employees of a telecommunications company in Togo, respectively. This diversity in the proportion of the workers with MetS in the mentioned studies could be explained by the different methodologies employed and the difference in defining criteria for MetS. Indeed, the prevalence of MetS varies from one study to another, depending on the defined criteria, the year of the study, as well as the age and gender of the population studied. The relatively high prevalence of MetS in the aforementioned studies indicate the importance of MetS in the workplace, which poses a real cardiometabolic risk. In fact, many factors were identified to be associated with MetS.

The population of this study consisted of adults and young workers with an average age of $38 \pm 8$ years. Besides, workers aged between 50 and 64 years were the least represented ones. Nevertheless, workers in this age group developed a higher risk of MetS in our study, with ORadjusted $=3.97 \mathrm{Cl} 95 \%[1.71-9.36]$. The same observations were made in other studies. Accordingly, Hinson et al in Togo, Kacem et al in Tunisia, and Ouédraogo et al in Burkina-Faso made the same observations [2, 12, 19], in which they found a significant association between age and MetS in subjects after age 40.

The population, in this study, was predominantly represented by males. This difference could be explained by the socio-cultural context in which tasks in ports are exclusively assigned to men. However, despite this high male representation, the prevalence of MetS was slightly higher in females than in males (19.4\% vs $17.7 \%)$. Several studies, particularly in black Africa, show this female predominance. Some hypotheses justify this female predominance in Africa. Accordingly, many women have a tendency to be obese, with living and working conditions of women being more stressful and sedentary when it comes to working in formal sectors. These factors expose women to high blood pressure and diabetes more than men. This was the case in the studies of Laraqui et al in Morocco (8.9\% vs 3.4\%) [10] and Ouédraogo et al in Burkina-Faso (25.8\% vs $15.5 \%$ ) [19]. Contrary to those findings, MetS was more common in men in the study by Hinson et al in Togo ( $25 \%$ vs $32.1 \%)$ and in Western countries [12]. What is the role of matrimonial situation in developing MetS?

The prevalence of MetS was lower in single employees (10.3\%) than in those living as couples (married and living together) (42.9\%). This difference could be explained by the higher socioeconomic level of workers living as couples. This result was different from that achieved by Hinson et al and Kacem et al [9, 12]. In fact, many households in Africa benefit from domestic assistance, with parents saving themselves from daily household chores. However, cleaning the house can be an opportunity for doing effective physical activity. May working conditions affect MetS development?

In this study, the risk of developing MetS was higher in administrative workers (17.9\%). The same observations were made in the study by Hinson et al (29.1\% vs $24.3 \%)$ in 2017 [12]. Likewise, the results of the study by Alavi et al (2015) on office workers were consistent with the present one [20]. This could be explained by the high calorie diet and the sedentary lifestyle among office workers with a prolonged sitting posture at work in front of computer screens, not being often very active. This way of working makes it easier for workers to gain weight. In the literature, several studies reported a statistically significant association between shift working and the risk of developing MetS [21]. Shift workers, although forming the majority of our study population, had a lower risk of developing MetS than day workers ( $16.3 \%$ vs $22.4 \%$ ). In addition, there was no causal link between the work period and developing MetS. The greater the work stress was, the higher the risk of developing MetS would lead to the occurrence of CVD and diabetes. In our study, the prevalence of MetS slightly increased among stressed workers compared to unstressed workers (19.0\% vs $17.3 \%$ ), being consistent with the results of Gombet et al in Congo [22]. Behavioral characteristics are often conditions associated with many chronic diseases. In the present study, a positive correlation was observed between alcohol consumption and MetS, being consistent with the studies by Konradi et al (2011) in Russia [23] as well as by Kang et al and Ouédraogo et al (2016) in Burkina-Faso [15]. Lifestyle habits have a strong impact on MetS development. 
In this study, $2.9 \%$ of the workers reported being active tobacco users. This rate was lower than the rate found in Benin according to the STEPS demographic and health survey in 2015, and than the rate found in the study by Hinson et al (7.5\%) (2017). In the present study, workers who had high calorie diets were more vulnerable to MetS development than others. However, no association was found in this respect. On the other hand, Kacem et al found a positive correlation between the high calorie diet of heavy eaters and MetS. The excessive consumption of salt, sugar, and lipids are the origin of metabolic disturbances that trigger the onset of arterial hypertension, obesity, and dyslipidemia [11], not being linked to MetS in our study. The frequency of no-fruit and vegetable consumption was very low with no significant association with MetS. A study conducted by Alavi et al in Iran showed a negative correlation between low fruit and vegetable consumption and MetS development [20]. Evidence shows that increasing fruit and vegetable consumption decreases the risk of developing MetS. Indeed, high consumption of fruit and vegetables exerts a beneficial and protective effect on cardio-metabolic risk factors thanks to being rich in fibers, essential antioxidants, vitamins, and minerals. Doing regular physical activity to accelerate the reduction of metabolic disorders (stress, obesity, and MetS) is linked to a sedentary lifestyle. The results of the studies by Hinson et al (2017) and Laraqui et al (2017) are consistent with this study [10, 12]. Contrary to the literature, physical activity at any level of energy consumption had no impact on the risk of developing MetS in our participants. Among all behavioral factors, alcoholism was the only factor associated with MetS in this study. This result was in line with other authors (Freiberg et al, Baik et al, and Fan et al) who showed that the quantity and frequency of alcohol consumption were strongly associated with the development of MetS [24-27]. Cardiovascular risk factors are often associated with developing MetS and can influence combined criteria of MetS.

The prevalence of MetS in overweight and obese workers was $24.8 \%$ and $28.1 \%$, respectively, amounting to the total prevalence of $52.9 \%$. However, it was slightly lower than that found by Yessoufou et al [28] in the general obese population in Benin (79\%). Being associated with insulin resistance, obesity is an important factor in the etiology of MetS, contributing to the development of hyperglycemia, hypertension, and hypercholesterolemia. The mean waist circumference was $90.1 \pm 12.3 \mathrm{~cm}$ with female predominance $(73.1 \%$ vs $36.1 \%)$ in this respect. This female predominance of abdominal obesity has been demonstrated in several studies, such as those of Laraqui et al $(73.3 \%$ vs $18.8 \%)$ and Hinson et al $(82.1 \%$ vs $50.8 \%)[10,12]$.

Several studies have reported increased blood pressure as one of the most common cardiovascular disorders accompanying MetS in Africa $[29,30]$. This was also the case in the present study where the prevalence of hypertension was $92.2 \%$ in subjects with MetS. In fact, in our study, $42.7 \%$ of the workers with risky blood pressure figures according to the definition of the FID 2009 had an increase in blood pressure levels. This rate was higher than the $25.3 \%$ rate reported in bank employees in the study by Hinson et al (2019) [31] and the $29.7 \%$ rate reported in the workplace in Abidjan (2001) [32]. Different socioprofessional groups could explain the variation in the percentages reported. In Benin, the result of the study (2016) by the WHO showed that the prevalence of arterial hypertension was $27.5 \%$ [33]. This rate was similar to the $27.3 \%$ and $27.9 \%$ rates found in 2008 and 2015, respectively, in the national STEPS report in Benin [34]. In addition, a study carried out by Amoussou-Guenou et al (2015) demonstrated the high prevalence of arterial hypertension (70\%) in type 2 diabetic patients in Benin [15]. This high prevalence could be explained by the close link between high blood pressure and diabetes in MetS, which explains why a family history of hypertension is associated with MetS.

We observed a higher proportion (24.6\%) of employees with blood glucose $\geq 5.5 \mathrm{mmol} / \mathrm{L}$ $(1.0 \mathrm{~g} / \mathrm{l})$ in our subjects than the prevalence of diabetes in the country in 2015, according to the STEPS survey [34]. Laraqui et al (2017) and Ouédraogo et al (2016) reported the prevalence of hyperglycemia at $72.6 \%$ and $38.1 \%$, respectively, in their studies $[10,19]$. The rate of known diabetic subjects in our subjects was $22.2 \%$, having been significantly higher than the prevalence of type 2 diabetes found by Djrolo et al in a populationbased study in Cotonou (2012) (4.6\%) [35].

The prevalence of HDL hypercholesterolemia and hypertriglyceridemia, although not significant, remained high. Besides, we found a relatively high rate of employees with low HDL cholesterolemia (55.7\%) compared to the proportions reported by Laraqui et al [10]. While the causes for that have not been fully known, lifestyle factors, such as eating habits, could be blamed.

This study provided some information on MetS status among workers in two companies in the city of Cotonou. The main strengths of this study were its comprehensiveness and inclusion of occupational factors in the analysis of associated factors. However, the study had some limitations. 
Accordingly, the study took into account only one screening event and did not use the psychomotor stress assessment tool, yet it employed a VASbased perceived stress tool. Besides, information bias could be due to the misreporting of the workers' lifestyle habits.

\section{Conclusion}

The prevalence of MetS among workers in two port companies in Cotonou, Benin, 2019, was high. Besides, the factors associated with MetS were age > 50 years, alcoholism, and overweight > $25 \mathrm{~kg} / \mathrm{m}^{2}$. In fact, knowledge of MetS facilitates the prevention of cardiovascular events in the workplace. Accordingly, the monitoring of clinical conditions of workers with MetS is necessary.

\section{Acknowledgement}

This article was taken from the $\mathrm{PhD}$ thesis in Medicine (Marie-Axelle Dossou-Togbé) from the University of Abomey-Calavi (Code 2204/2019). We would like to thank all the individuals who participated in the study. We would also like to express our sincere gratitude to the administrative authorities of each of the companies for assisting us with the study.

Conflict of interest: None declared.

\section{References}

1. Boursier V. [Metabolic syndrome]. J Mal Vasc 2006; 31(4 Pt 1):190-201.

2. Kesse-Guyot E, Ahluwalia N, Lassale $C$, Hercberg S, Fezeu L, Lairon D. Adherence to Mediterranean diet reduces the risk of metabolic syndrome: a 6-year prospective study. Nutr Metab Cardiovasc Dis 2013; 23(7):677-83.

3. Canuto R, Pattussi MP, Macagnan JB, Henn $\mathrm{RL}$, Olinto M. Metabolic syndrome in fixed-shift workers. Rev Saude Publica 2015; 49:30.

4. World Health Organization. [Les maladies cardiovasculaires dans la région africaine: situation actuelle et perspectives (document AFR/RC55/12)]. The 55th Session Regional Committee for Africa; 2005 Aug 22-26; Africa Regional Office, Maputo, Mozambique.

5. International Diabetes Federation. The IDF Consensus Worldwide Definition of Metabolic Syndrome. Brussels, Belgium; International Diabetes Federation: 2006.

6. Islam SM, Purnat TD, Phuong NT, Mwingira U, Schacht K, Froschl G. Non-communicable diseases (NCDs) in developing countries: a symposium report. Global Health 2014; 10:81.

7. Matheus AS, Tannus LR, Cobas RA, Palma CC, Negrato CA, Gomes MB. Impact of diabetes on cardiovascular disease: an update.
Int J Hypertens 2013; 2013:653789.

8. Alberti KG, Eckel RH, Grundy SM, Zimmet PZ, Cleeman JI, Donato KA, et al. Harmonizing the metabolic syndrome: a joint interim statement of the International Diabetes Federation Task Force on Epidemiology and Prevention; National Heart, Lung, and Blood Institute; American Heart Association; World Heart Federation; International Atherosclerosis Society; and International Association for the Study of Obesity. Circulation 2009; 120(16):1640-5.

9. Kacem I, Maoua M, Hasni Y, Kalboussi $H$, Hafsia M, Souguir S, et al. Evaluation of the risk of metabolic syndrome among shift workers in Tunisia. East Mediterr Health J 2019; 25(10):677-85.

10. Laraqui $O$, Laraqui $S$, Manar $N$, Loukili $M$, Deschamps F, Laraqui C. Screening and Prevalence of the Main Components of the Metabolic Syndrome among Health Care Workers in Morocco. Int J Innov Appl Stud 2017; 20(3):863-9.

11. Ilboudo A, Yameogo TM, Kyelem GC, Drabo LA, Bagbila A, Ouedraogo SM, et al. Syndrome métabolique et autres facteurs de risques cardiovasculaires (FDRCV) en milieu professionnel: à propos de 344 travailleurs examinés à Ouagadougou au Burkina Faso. Ann Endocrinol (Paris) 2017; 78(4):439-40.

12. Hinson AV, Kpata S, Wognin BS, Mikponhoue $R$, Adjobimey $M$, Ayelo $P$. Prevalence of Metabolic Syndrome and its Associated Factors Among the Employees of a Commercial Company in Togo. SciFed J Public Health 2017; 1(2):1-11.

13. Walle B, Reba K, Debela Y, Tadele K, Biadglegne F, Gutema $\mathrm{H}$. Prevalence of Metabolic Syndrome and Factors Associated with It among Adults of West Gojjam: A Community-Based Cross-Sectional Study. Diabetes Metab Syndr Obes 2021; 14:875-83.

14. Aliyu SU, Chiroma AS, Jajere AM, Gujba FK. Prevalence of Physical Inactivity, Hypertension, Obesity and Tobacco Smoking: A Case of NCDs Prevention among Adults in Maiduguri, Nigeria. Am J Med Sci Med 2015; 3(4):39-47.

15. Amoussou-Guenou D, Wanvoegbe A, Agbodandé A, Dansou A, Tchabi $Y$, Eyissè $Y$, et al. Prevalence and Risk Factors of Hypertension in Type 2 Diabetics in Benin. $J$ Diabetes Mellitus 2015; 5(4):227-32.

16. Assoumanou MG, Dovonou AC, Ngome MR, Akpona SA. [Prevalence of metabolic syndrome in adult hypertensive subjects in health facilities in Parakou (Benin)]. Int J Biol Chem Sci 2012; 6(4):1419-27.

17. Yessoufou AG, Behanzin J, Djihoumeto E, Isstina ZA, Ahokpe $M$, Sezan A. [Epidemiological aspects of metabolic syndrome in the obese population of the municipality of Ouidah in southwestern Benin]. Anthropo 2015; 33:111-6. 
18. Kouassi KC, Pessinaba S, Kaaga L, Lamboni C, Damorou F. [Prevalence of pre-diabetes, metabolic syndrome, diabetes and dyslipidemia in 350 subjects recruited at the Hédzranawoé market in Lomé (Togo)]. Int $\mathrm{J}$ Biol Chem Sci 2020; 14(8):2713-23.

19. Ouédraogo SM, Tougouma JB, Sanon/Lompo S, Maiga S, Yaméogo TM, Kyelem CG, et al. [Metabolic syndrome and cardiac metabolic risk in occupational environment]. Afr J Intern Med 2016; 3(1):47-55.

20. Alavi SS, Makarem J, Mehrdad R, Abbasi M. Metabolic syndrome: a common problem among office workers. Int J Occup Environ Med 2015; 6(1):34-40.

21. Kim KY, Yun JM. Analysis of the association between health-related and work-related factors among workers and metabolic syndrome using data from the Korean National Health and Nutrition Examination Survey (2016). Nutr Res Pract 2019; 13(5):444-51.

22. Gombet $\mathrm{T}$, Longo-Mbenza B, Ellenga-Mbolla B, Ikama MS, Mokondjimobe E, Kimbally-Kaky G, et al. Aging, female sex, migration, elevated HDL-C , and inflammation are associated with prevalence of metabolic syndrome among African bank employees. Int J Gen Med 2012; 5:495-503.

23. Konradi AO, Rotar OP, Korostovtseva LS, Ivanenko VV, Solntcev VN, Anokhin SB, et al. Prevalence of metabolic syndrome components in a population of bank employees from St. Petersburg, Russia. Metab Syndr Relat Disord 2011; 9(5):337-43.

24. Ngombe LK, Cowgill K, Monga BB, llunga BK, Stanis WO, Numbi OL. [Prevalence of hypertension in the population of the millers of the city of Lubumbashi, Democratic Republic of Congo]. Pan Afr Med J 2015; 22:152.

25. Freiberg MS, Cabral HJ, Heeren TC, Vasan RS, Curtis Ellison R; Third National Health and Nutrition Examination Survey. Alcohol consumption and the prevalence of the metabolic syndrome in the US.: a crosssectional analysis of data from the Third National Health and Nutrition Examination Survey. Diabetes Care 2004; 27(12):2954-9.

26. Baik I, Shin C. Prospective study of alcohol consumption and metabolic syndrome. Am J
Clin Nutr 2008; 87(5):1455-63.

27. Fan AZ, Russell M, Naimi T, Li Y, Liao $Y$, Jiles $R$, et al. Patterns of alcohol consumption and the metabolic syndrome. J Clin Endocrinol Metab 2008; 93(10):3833-8.

28. Yessoufou AG, Behanzin J, Djihoumeto $E$, Isstina ZA, Ahokpe M, Sezan A. [Epidemiological Aspects of Metabolic Syndrome in the Obese Population of the Municipality Ouidah in Southwestern Benin]. Antrop 2015; 33:111-6.

29. Ogbera AO. Prevalence and gender distribution of the metabolic syndrome. Diabetol Metab Syndr 2010; 2:1.

30. Ulasi II, Ijoma CK, Onodugo OD. A communitybased study of hypertension and cardiometabolic syndrome in semi-urban and rural communities in Nigeria. BMC Health Serv Res 2010; 10:71.

31. Hinson AV, Affo Y, Mikponhoue R, Adjobime M, Houenassi M, Fayomi B. Epidemiological Aspects of the High Blood Pressure in Occupational Environment-Case of a Bank in Cotonou (Benin). J Environ Sci Public Health 2019; 3(3):435-49.

32. Koffi NM, Sally SJ, Kouame P, Silue K, Diarra Nama AJ. [Facies of arterial hypertension in the workplace in Abidjan]. Black Afr Med 2001; 48(6):257-60.

33. Bio A, Toyi SSM, Yoka J, Djego GJ, Awede B, Laleye $A$, et al. [Contribution to knowledge of the main antihypertensive plants used in traditional medicine in Bassila (Benin, West Africa)]. Pharm Series Med Trad Afr 2015; 17(2):8-18.

34. Ministry of Health, National Directorate of Health Protection, National Program for the Fight against Non-Communicable Diseases (PNLMNT). Final Report of the WHO "STEPSWise" Noncommunicable Disease Risk Factor Surveillance Survey 2015 Steps Survey. 2016 Sep. p 139.

35. Djrolo F, Houinato D, Gbary A, Akoha R, Djigbénoudé $O$, Sègnon J. Prévalence du diabète sucré dans la population adulte à Cotonou, Bénin: Prevalence of diabetes mellitus in the adult population at Cotonou, Benin. Médecine des Maladies Métaboliques 2012; 6(2):167-9. 